\title{
Vascular procedures in patients with left ventricular assist devices: single-center experience
}

\author{
Saad Rustum ${ }^{1}$. Julia Neuser ${ }^{1}$. Jan Dieter Schmitto ${ }^{1}$ - Thomas Aper ${ }^{1}$ - Jasmin Sarah Hanke ${ }^{1}$ - Axel Haverich ${ }^{1}$. \\ Mathias Wilhelmi ${ }^{1}$
}

Received: 27 November 2020 / Revised: 29 March 2021 / Accepted: 30 March 2021 / Published online: 27 May 2021

(C) The Author(s) 2021

\begin{abstract}
Objective A growing number of patients suffering from heart failure is living with a left ventricular assist device (LVAD) and is in the need for non-cardiac surgery. Vascular procedures due to ischemia, bleeding, or other device-related complications may be required and pose a challenge to the caregivers in terms of monitoring and management of these patients. Therefore, we reviewed our experience with LVAD patients undergoing vascular surgery.

Methods From January 2010 until March 2017, a total of 54 vascular procedures were performed on 41 LVAD patients at our institution. Patient records were reviewed retrospectively in terms of incidence of LVAD-related complications, including thrombosis, stroke, bleeding, wound healing, and survival associated with vascular surgery. The type of surgery was recorded, as well as various clinical demographic variables.

Results Vascular procedures were performed in 35 men (85.4\%) and 6 women (14.6\%) with LVADs. There were no perioperative strokes, device thromboses, or device malfunctions. Thirty-day mortality overall was $26.8 \%$ (eleven patients), with most patients dying within 30 days after LVAD implantation due to multi-organ failure. In 25 procedures (46.3\%), a blood transfusion was necessary.

Conclusion Patients on LVAD support are a complex cohort with a high risk for perioperative complications. In a setting where device function and anticoagulation are monitored closely, vascular surgery in these patients is feasible with an acceptable perioperative risk.
\end{abstract}

Keywords Vascular surgery $\cdot$ LVAD $\cdot$ Bleeding $\cdot$ Thrombosis

\section{Introduction}

Left ventricular assist devices (LVADs) have become a viable therapeutic strategy for bridge to transplant (BTT) and destination therapy (DT) in the failing heart [1-4]. With increase in LVAD use and technical progress $[5,6]$, more patients require non-cardiac surgery or develop complications that are leading to surgical interventions [7-12]. These complications are often related to bleeding, infection, or ischemia and may require a vascular surgical procedure $[13,14]$. These patients present

Saad Rustum and Julia Neuser contributed equally to this work.

Saad Rustum

Rustum.saad@mh-hannover.de

1 Clinic for Cardiothoracic, Transplantation and Vascular Surgery, Hannover Medical School, Carl-Neuberg-Straße 1,

30625 Hannover, Germany multiple challenges to the caregivers and are on long-term anticoagulation with Coumadin and anti-platelet therapy, additionally [15]. Consequently, at the time of surgery, anticoagulation management must balance the potential for thromboembolisms and device thrombosis on the one hand with the risk of bleeding on the other [16, 17]. Previous studies have reported on general non-cardiac surgery in LVAD patients but vascular surgical procedures have not been extensively characterized $[10,18,19]$. Therefore, we reviewed our institutional experience with vascular procedures on patients while on LVAD support.

\section{Methods}

From January 2010 until March 2017, a total of 54 vascular procedures were performed on $41 \mathrm{LVAD}$ patients. During the same time, a total of 498 ventricular assist devices were 
implanted at our institution and approximately 4800 vascular surgeries were performed. Only 77 (15.5\%) patients were women. We reviewed our clinical records retrospectively with a specific focus on incidence of LVAD-related complications, including thrombosis, stroke, bleeding, wound healing, and survival associated with vascular procedures. The study was conducted in accordance with the Declaration of Helsinki. The authors received no specific funding for this work. The type of vascular procedures was recorded as well as the duration of LVAD support at the time of the procedure. Various clinical demographic variables were recorded, including age, sex, etiology of heart failure, peripheral arterial disease (PAD), smoking status, diabetes, renal insufficiency, and the anticoagulation regimen at the time of surgery.

\section{Data analysis}

Data are presented as frequency distributions and percentages. Continuous variables are summarized as mean \pm standard deviation or median (range) and were tested for normal distribution with the Kolmogorov-Smirnov test. Differences were analyzed using a $t$-test. If normal distribution was not applicable, the Mann-Whitney $U$-test was performed. Categorical variables were presented in absolute numbers and percentages. For all analysis, a value of $p<0.05$ was considered statistically significant.

\section{Results}

\section{Demographics}

Vascular procedures were performed in 35 men (85.4\%) and 6 women (14.6\%) with LVADs. The different assist devices were HeartWare (HeartWare ${ }^{\circ}$, Medtronic, MN, USA) in 30 patients $(55.6 \%)$, HeartMate II (Abbott, Inc, IL, USA) in ten patients (18.5\%), and HeartMate III (Abbott, Inc, IL, USA) in one patient $(1.9 \%)$. Median age was 56 (48-59) years. The etiology of heart failure was non-ischemic dilated cardiomyopathy in 18 patients (43.9\%) and ischemic cardiomyopathy in 23 patients $(56.1 \%)$. Ten patients $(24.4 \%)$ were suffering from diabetes mellitus and PAD was present in ten patients (24.4\%). Twenty-four (58.5\%) patients had an active smoking status. A preoperative renal insufficiency was known in 21 patients $(51.2 \%)$ and ten patients $(24.4 \%)$ required hemodialysis.

\section{Types of procedures}

There were 54 procedures performed in 41 different patients. A detailed summary of the procedures is presented in Table 1. Thirty-one $(57.4 \%)$ procedures were for arterial reconstruction, including thrombendarteriectomy and embolectomy, and are presented in Table 2. Procedures related to hemodialysis shunts were done in six patients $(11.1 \%)$. Amputations (three minor, two major) were necessary in five cases $(9.3 \%)$
Table 1 Summary of vascular procedures

\begin{tabular}{lll}
\hline Surgical status & Indication & $n$ \\
\hline $\begin{array}{l}\text { Emergency } \\
\text { Reconstruction of carotid artery and jugular vein }\end{array}$ & Failed positioning of central venous catheter & 1 \\
$\begin{array}{l}\text { Thrombendarteriectomy femoral artery }+/- \text { PTA or } \\
\text { bypass }\end{array}$ & Acute ischemia of the lower limb & 8 \\
Embolectomy (via femoral access) & Acute ischemia of the lower limb & 5 \\
Open surgical ECMO implantation & Additional extracorporal support and calcified vessels & 2 \\
Shunt resection & High-volume shunt in acute heart failure and bleeding & 1 \\
Open surgical distal perfusion catheter placement & Acute ischemia of the lower limb & 3 \\
$\quad$ (on ECMO) & & \\
Explantation of a tunneled catheter & Sepsis & 1 \\
Forefoot amputation & Sepsis & 1 \\
Elective & & 4 \\
Embolectomy (via femoral access) & Ischemia of the lower limb & 2 \\
Thrombendarteriectomy carotid artery & Cartotid artery stenosis & 3 \\
Femoral AV-fistula resection & Heart failure & 3 \\
Thrombendarteriectomy femoral artery $+/-$ PTA or & Peripheral artery disease & 3 \\
$\quad$ bypass & & 1 \\
Open surgical ECMO explantation & ECMO weaning & 1 \\
Stent implantation in LVAD outflowgraft & Suture aneurysm outflowgraft \\
Carotid artery filter implantation & Cerebral protection during LVAD exchange (ventricular & thrombus) \\
Shunt (implantation or revision) & Hemodialysis & 5 \\
Tunneled dialysis catheter implantation & Hemodialysis & 6 \\
Toe amputation & Necrosis & 2 \\
Leg amputation & Peripheral artery disease (Fontaine IV) \\
\hline
\end{tabular}


Table 2 Reconstructive vascular surgery

\begin{tabular}{ll}
\hline$n$ & 31 \\
\hline Emergency & 16 \\
Age & $56.5(48.2-59.5)$ \\
BMI & $25.2(23.1-26.8)$ \\
Sex (male) & $23(74.2 \%)$ \\
Diabetes & $7(22.5 \%)$ \\
PAD & $7(22.5 \%)$ \\
Etiology of heart failure DCM & $10(32.2 \%)$ \\
Renal insufficiency & $12(38.7 \%)$ \\
Dialysis & $3(9.7 \%)$ \\
Smoker & $16(51.6 \%)$ \\
INR pre & $1.79 \pm 0.6$ \\
Pre-operative ASS & $6(19.4 \%)$ \\
Pre-operative clopidogrel & $9(29.0 \%)$ \\
Within 3 days of LVAD implantation & $9(29.0 \%)$ \\
Duration of support & $193(3-772)$ \\
On ECMO support & $7(22.5 \%)$ \\
General anesthesia & $31(100.0 \%)$ \\
Duration of surgery & $93.5(50-131)$ \\
Perioperative transfusion & $9(29.0 \%)$ \\
Surgical re-exploration & $0(0 \%)$ \\
Stroke & $0(0 \%)$ \\
Device malfunction & $0(0 \%)$ \\
Wound complications & $5(16.1 \%)$ \\
30-d mortality in elective procedures & $0(0 \%)$ \\
\hline &
\end{tabular}

Abbreviation: $B M I$, body mass index

due to vascular complications. In two patients (3.7\%), endovascular stenting was performed and ten patients (18.5\%) received a catheter-based procedure (tunneled dialysis catheter or distal perfusion catheter while on extracorporeal membrane oxygenation (ECMO) support).

\section{Timing of surgery}

Twenty-two cases $(40.7 \%)$ were performed as an emergency procedure and eleven surgeries $(20.4 \%)$ have been performed within 3 days after LVAD implantation. In 14 procedures (25.9\%), the patient was on ECMO support in addition to the assist device. During 44 (81.5\%) surgeries, an arterial line was placed to monitor the blood pressure; in ten cases $(18.5 \%)$, a cuff sufficed when the patients had appropriate pulsatility.

\section{Morbidity and mortality after vascular surgery}

There were no perioperative strokes, device thromboses, device malfunctions, or surgical re-explorations due to bleeding. Thirty-day mortality overall was $26.8 \%$ (eleven patients), with most patients dying within 30 days after LVAD implantation due to multi-organ failure. In 25 procedures (46.3\%), a blood transfusion (packed red blood cells, PRBCs) was necessary. Surgical re-exploration due to bleeding did not occur; however, in nine patients $(16.7 \%)$, there was prolonged wound healing.

\section{Comparison of elective and emergency procedures}

The results of this comparison are presented in Table 3. There was a significant difference in preoperative international normalized ratio (INR) $(p=0.021)$ with a higher INR before emergency procedures. A significant number of emergency procedures was performed within 3 days of LVAD implantation $(p=0.017)$ as well as on ECMO support $(p=0.039)$. The necessity for transfusion of PRBCs was higher in emergency procedures $(68.2 \%$ vs. $31.3 \%)$. The 30 -day mortality was also higher in patients requiring emergent surgery $(40.9 \%$ vs. $6.3 \%$ ). Comorbidities, duration of surgery, and complexity of procedures are comparable between the groups.

\section{Comparison of patients who did and did not require transfusion of PRBCs}

Results of the analysis regarding the necessity of PRBC transfusion are presented in Table 4. A significant number of procedures where PRBCs were administered was performed within 3 days of LVAD implantation $(p=0.009)$, on ECMO support $(p \leq 0.001)$, or as emergency cases $(p=0.008)$. All patients who received blood have been under general anesthesia and more complex vascular reconstructions $(80.0 \%)$ have been performed. INR was comparable in both groups (1.57 vs. 1.48); however, a higher number of patients who did not receive a PRBC transfusion was on anti-platelet therapy with clopidogrel $(p=0.021)$.

\section{Discussion}

With a growing number of implanted LVADs, especially as a destination therapy, patients are older and present with more comorbidities [7, 20,21]. On the other hand, younger patients on bridge to transplant therapy live a more active lifestyle and require vascular surgery due to peripheral artery disease which might limit their everyday activities. Therefore, an increasing number of patients is in the need for non-cardiac surgical procedures. In this study, we present the outcomes of vascular interventions in patients on a left ventricular assist device who have been operated at our institution. To our notice, our cohort of 41 patients, where 54 vascular procedures were performed, is one of the largest cohorts examined [18, 19,22].

Several aspects of LVAD therapy must be considered when performing vascular surgeries in these patients, 
Table 3 Comparison of emergency and elective procedures

\begin{tabular}{|c|c|c|c|}
\hline & Emergency & Elective & $p$-value \\
\hline$n$ & 22 & 32 & \\
\hline Age & $56.5(51.8-61)$ & $56.0(50-59)$ & 0.744 \\
\hline BMI & $26.2 \pm 4.4$ & $24.4(23.2-30.3)$ & 0.951 \\
\hline Sex (male) & $20(90.9 \%)$ & $29(90.6 \%)$ & 0.972 \\
\hline Diabetes & $6(27.3 \%)$ & $9(28.1 \%)$ & 0.946 \\
\hline PAD & $4(18.2 \%)$ & $12(37.5 \%)$ & 0.130 \\
\hline \multicolumn{4}{|l|}{ Etiology of heart failure } \\
\hline DCM & $11(50 \%)$ & $14(43.8 \%)$ & 0.654 \\
\hline ICM & $11(50 \%)$ & $18(56.3 \%)$ & 0.373 \\
\hline Renal insufficiency & $10(45.5 \%)$ & $22(68.7 \%)$ & 0.090 \\
\hline Dialysis & $4(18.2 \%)$ & $13(40.6 \%)$ & 0.084 \\
\hline Smoker & $12(54.5 \%)$ & $15(46.9 \%)$ & 0.583 \\
\hline INR pre & $1.99 \pm 0.7$ & $1.46 \pm 0.3$ & 0.021 \\
\hline Pre-operative ASS & $3(13.6 \%)$ & $5(15.6 \%)$ & 0.841 \\
\hline Pre-operative clopidogrel & $8(36.4 \%)$ & $14(43.8 \%)$ & 0.591 \\
\hline Within 3 days of LVAD implantation & $8(36.4 \%)$ & $3(9.4 \%)$ & 0.017 \\
\hline Duration of support & $236(2-886)$ & $337(53-643)$ & 0.413 \\
\hline On ECMO support & $9(40.9 \%)$ & $5(15.6 \%)$ & 0.039 \\
\hline General anesthesia & $21(95.5 \%)$ & $27(84.4 \%)$ & 0.207 \\
\hline Duration of surgery & $57(38-113)$ & $93.3 \pm 55$ & 0.202 \\
\hline \multicolumn{4}{|l|}{ Type of surgery } \\
\hline Vascular reconstruction & $16(72.7 \%)$ & $15(46.9 \%)$ & 0.061 \\
\hline Stent & $0(0 \%)$ & $2(6.3 \%)$ & 0.236 \\
\hline Shunt & $1(4.5 \%)$ & $5(15.6 \%)$ & 0.207 \\
\hline Catheter-based procedure & $4(18.2 \%)$ & $6(18.8 \%)$ & 0.958 \\
\hline Amputation & $1(4.5 \%)$ & $4(12.5 \%)$ & 0.326 \\
\hline Perioperative transfusion & $15(68.2 \%)$ & $10(31.3 \%)$ & 0.008 \\
\hline Surgical re-exploration & $0(0 \%)$ & $0(0 \%)$ & \\
\hline Stroke & $0(0 \%)$ & $0(0 \%)$ & \\
\hline Device malfunction & $0(0 \%)$ & $0(0 \%)$ & \\
\hline Wound complications & $6(27.3 \%)$ & $3(9.4 \%)$ & 0.348 \\
\hline 30-d mortality & $8(36.4 \%)$ & $2(6.3 \%)$ & 0.002 \\
\hline
\end{tabular}

including high levels of anticoagulation or acquired von Willebrand disease $[11,23]$. The mean INR of our entire cohort was $1.68 \pm 0.58$ and therefore in the therapeutic range where an extremely low frequency of thromboembolic events has been reported [24]. In addition, anti-platelet therapy either with aspirin ( 8 patients) or clopidogrel (22 patients) was administered. When comparing elective and emergency vascular procedures in LVAD patients at our institution, the INR was significantly higher in an emergency setting, while antiplatelet therapy was comparable. There was a significantly higher rate of PRBC transfusion in the emergency group $(68.2 \%$ vs. $31.3 \%)$. However, when comparing patients who received and who did not receive PRBCs perioperatively, no significant difference was found in the INR at the time of surgery. When analyzing the patients who underwent an emergency vascular procedure, a substantial number was on simultaneous ECMO support (40.9\%), and in 36.4\%, the surgery was performed within the first 3 days after LVAD implantation. We believe that this constellation has led to the significantly higher rate of PRBC transfusion in emergency procedures. It is also an explanation for the significantly higher 30 -day mortality rate (36.4\% vs. $6.3 \%$ ) in the emergency group. The patient cohort that did not require a PRBC transfusion had a significant higher rate of patients receiving clopidogrel $(p=0.021)$ as additional anti-platelet therapy. It seems that whether patients were given aspirin or clopidogrel had no substantial influence on perioperative bleeding in our cohort. In addition, the majority of procedures (80\%) in the group that received a blood transfusion were complex vascular reconstruction $(p=0.002)$. 
Table 4 Comparison of patients who did and did not require PRBC transfusion

\begin{tabular}{|c|c|c|c|}
\hline & Required PRBCs & No PRBCs required & $p$-value \\
\hline$n$ & 25 & 29 & \\
\hline Age & $56(52-60)$ & $56(51-60)$ & 0.869 \\
\hline BMI & $25.3 \pm 4.68$ & $26.3(23.5-30.7)$ & 0.150 \\
\hline Sex (male) & $23(92.0 \%)$ & $26(89.7 \%)$ & 0.769 \\
\hline Diabetes & $7(28.0 \%)$ & $8(27.6 \%)$ & 0.973 \\
\hline PAD & $8(32.0 \%)$ & $8(27.6 \%)$ & 0.726 \\
\hline \multicolumn{4}{|l|}{ Etiology of heart failure } \\
\hline $\mathrm{DCM}$ & $15(60.0 \%)$ & $10(45.5 \%)$ & 0.063 \\
\hline $\mathrm{ICM}$ & $10(40.0 \%)$ & $19(65.6 \%)$ & 0.031 \\
\hline Renal insufficiency & $13(52.0 \%)$ & $19(65.5 \%)$ & 0.381 \\
\hline Dialysis & $4(16.0 \%)$ & $13(44.8 \%)$ & 0.024 \\
\hline Smoker & $14(56.0 \%)$ & $13(44.8 \%)$ & 0.417 \\
\hline INR & $1.48(1.23-1.93)$ & $1.57(1.38-1.78)$ & 0.768 \\
\hline Pre-operative ASS & $2(8.0 \%)$ & $6(20.7 \%)$ & 0.198 \\
\hline Pre-operative clopidogrel & $6(24.0 \%)$ & $16(55.2 \%)$ & 0.021 \\
\hline Within 3 days of LVAD implantation & $9(36.0 \%)$ & $2(6.9 \%)$ & 0.009 \\
\hline Duration of support & $63(49-115)$ & $373(201-768)$ & 0.077 \\
\hline On ECMO support & $12(48.0 \%)$ & $2(6.9 \%)$ & $<0.001$ \\
\hline Emergency & $15(60.0 \%)$ & $7(24.1 \%)$ & 0.008 \\
\hline General anesthesia & $25(100 \%)$ & $23(79.3 \%)$ & 0.017 \\
\hline Duration of surgery & $95.4 \pm 54$ & $56(14-169)$ & 0.077 \\
\hline \multicolumn{4}{|l|}{ Type of surgery } \\
\hline Vascular reconstruction & $20(80.0 \%)$ & $11(37.9 \%)$ & 0.002 \\
\hline Stent & $1(4.0 \%)$ & $1(3.4 \%)$ & 0.916 \\
\hline Shunt & $1(4.0 \%)$ & $5(17.2 \%)$ & 0.126 \\
\hline Catheter-based procedure & $2(8.0 \%)$ & $8(27.6 \%)$ & 0.067 \\
\hline Amputation & $1(4.0 \%)$ & $4(13.8 \%)$ & 0.220 \\
\hline Surgical re-exploration & $0(0 \%)$ & $0(0 \%)$ & \\
\hline Stroke & $0(0 \%)$ & $0(0 \%)$ & \\
\hline Device malfunction & $0(0 \%)$ & $0(0 \%)$ & \\
\hline Wound complications & $5(20.0 \%)$ & $4(13.8 \%)$ & 0.916 \\
\hline 30-d mortality & $8(32.0 \%)$ & $2(6.9 \%)$ & 0.051 \\
\hline
\end{tabular}

The types of procedures performed in an elective setting were analogous to the procedures performed urgently. Surgical re-exploration due to bleeding was not required in any patient; at the same time, none of our patients suffered from stroke or device thrombosis with resulting device malfunction. However, there was a 30-day mortality of $18.5 \%$ overall. Considering that 39 of our vascular procedures have been performed within the first month of LVAD implantation, and a total of 14 procedures were performed on simultaneous ECMO support, the mortality rate is for the most part due to complications regarding the heart failure and is within the reported mortality range after LVAD implantation [25-27].

There was prolonged wound healing in a total of nine cases $(4.9 \%)$ which entailed escalated or extended antibiotic therapy. Moreover, those patients were seen by our wound managers (registered nurses with special training in wound care) on a daily basis. Wound complications were mostly observed after femoral access, especially in patients with a higher body mass index (BMI). In this high-risk patient cohort, we anticipated a prolonged wound healing; therefore, we used special wound dressing prophylactically (e.g., antibacterial dressing). Although surgical re-exploration was not necessary, meticulous wound care in LVAD patients is vital to avoid blood stream infections and further device complications [28].

\section{Limitations}

A limitation of this study is the heterogeneity of the performed vascular procedures with different risks and complication 
rates. The study has been performed retrospectively, was nonrandomized, and only reflects a single-center experience.

\section{Conclusion}

Our study represents the largest number of cases where vascular intervention is performed in patients on LVAD support. It underlines that vascular surgery after LVAD is feasible as long as ventricular assist device (VAD)-specific pitfalls are addressed. Besides the heart failure with all its consequences, the anticoagulation regimen and acquired von Willebrand disease can cause further complications. In an experienced center where device function is monitored closely perioperatively, vascular surgery in LVAD patients can be performed safely with a low rate of complications.

Funding Open Access funding enabled and organized by Projekt DEAL.

\section{Declarations}

Ethical approval Not required at our institution for retrospective studies.

Informed consent Not required at our institution for retrospective studies.

Conflict of interest The authors declare no competing interests.

Open Access This article is licensed under a Creative Commons Attribution 4.0 International License, which permits use, sharing, adaptation, distribution and reproduction in any medium or format, as long as you give appropriate credit to the original author(s) and the source, provide a link to the Creative Commons licence, and indicate if changes were made. The images or other third party material in this article are included in the article's Creative Commons licence, unless indicated otherwise in a credit line to the material. If material is not included in the article's Creative Commons licence and your intended use is not permitted by statutory regulation or exceeds the permitted use, you will need to obtain permission directly from the copyright holder. To view a copy of this licence, visit http://creativecommons.org/licenses/by/4.0/.

\section{References}

1. Miller LW, Pagani FD, Russell SD, et al. Use of a continuous-flow device in patients awaiting heart transplantation. N Engl J Med. 2007;357:885-96.

2. Slaughter MS, Rogers JG, Milano CA, et al. Advanced heart failure treated with continuous-flow left ventricular assist device. N Engl J Med. 2009;361:2241-51.

3. Rose EA, Gelijns AC, Moskowitz AJ, et al. Long-term use of a left ventricular assist device for end-stage heart failure. N Engl J Med. 2001;345:1435-43.

4. Schmitto JD, Hanke JS, Rojas S, et al. Circulatory support exceeding five years with a continuous-flow left ventricular assist device for advanced heart failure patients. J Cardiothorac Surg. 2015;10: 107.
5. Schmitto JD, Molitoris U, Haverich A, Strueber M. Implantation of a centrifugal pump as a left ventricular assist device through a novel, minimized approach: upper hemisternotomy combined with anterolateral thoracotomy. J Thorac Cardiovasc Surg. 2012;143: 511-3.

6. Schmitto JD, Hanke JS, Rojas SV, Avsar M, Haverich A. First implantation in man of a new magnetically levitated left ventricular assist device (HeartMate III). J Heart Lung Transplant. 2015;34:858-60.

7. Slaughter MS, Pagani FD, Rogers JG, et al. Clinical management of continuous-flow left ventricular assist devices in advanced heart failure. J Heart Lung Transplant.2010;29:S1-39.

8. Schmid C, Wilhelm M, Dietl KH, Schmidt C, Hammel D, Scheld $\mathrm{HH}$. Noncardiac surgery in patients with left ventricular assist devices. Surgery. 2001;129:440-4.

9. Garatti A, Bruschi G, Colombo T, et al. Noncardiac surgical procedures in patient supported with long-term implantable left ventricular assist device. Am J Surg. 2009;197:710-4.

10. Morgan JA, Paone G, Nemeh HW, et al. Non-cardiac surgery in patients on long-term left ventricular assist device support. J Heart Lung Transplant.2012;31:757-63.

11. Roberts SM, Hovord DG, Kodavatiganti R, Sathishkumar S. Ventricular assist devices and non-cardiac surgery. BMC Anesthesiol. 2015;15:185.

12. Degnan M, Brodt J, Rodriguez-Blanco Y. Perioperative management of patients with left ventricular assist devices undergoing noncardiac surgery. Ann Card Anaesth. 2016;19:676-86.

13. Park SJ, Tector A, Piccioni W, et al. Left ventricular assist devices as destination therapy: a new look at survival. J Thorac Cardiovasc Surg. 2005;129:9-17.

14. Long JW, Kfoury AG, Slaughter MS, et al. Long-term destination therapy with the HeartMate XVE left ventricular assist device: improved outcomes since the REMATCH study. Congest Heart Fail. 2005;11:133-8.

15. Oleyar M, Stone M, Neustein SM. Perioperative management of a patient with a nonpulsatile left ventricular-assist device presenting for noncardiac surgery. J Cardiothorac Vasc Anesth. 2010;24:8203.

16. Klovaite J, Gustafsson F, Mortensen SA, Sander K, Nielsen LB. Severely impaired von Willebrand factor-dependent platelet aggregation in patients with a continuous-flow left ventricular assist device (HeartMate II). J Am Coll Cardiol. 2009;53:2162-7.

17. Boyle AJ, Russell SD, Teuteberg JJ, et al. Low thromboembolism and pump thrombosis with the HeartMate II left ventricular assist device: analysis of outpatient anti-coagulation. J Heart Lung Transplant.2009;28:881-7.

18. Arnaoutakis GJ, Bittle GJ, Allen JG, et al. General and acute care surgical procedures in patients with left ventricular assist devices. World J Surg. 2014;38:765-73.

19. Davis J, Sanford D, Schilling J, Hardi A, Colditz G. Systematic review of outcomes after noncardiac surgery in patients with implanted left ventricular assist devices. ASAIO J. 2015;61:648-51.

20. Pagani FD, Miller LW, Russell SD, et al. Extended mechanical circulatory support with a continuous-flow rotary left ventricular assist device. J Am Coll Cardiol. 2009;54:312-21.

21. Hanke JS, Rojas SV, Avsar M, et al. HeartWare left ventricular assist device for the treatment of advanced heart failure. Futur Cardiol. 2016;12:17-26.

22. Chen CW, Dumon KR, Shaked O, Acker MA, Atluri P, Dempsey DT. Non-cardiac surgery in patients with continuous-flow left ventricular assist devices: a single institutional experience. J Investig Med. 2017;65:912-8.

23. Baghai M, Heilmann C, Beyersdorf F, et al. Platelet dysfunction and acquired von Willebrand syndrome in patients with left ventricular assist devices. Eur J Cardiothorac Surg. 2015;48:421-7. 
24. John R, Kamdar F, Liao K, et al. Low thromboembolic risk for patients with the Heartmate II left ventricular assist device. J Thorac Cardiovasc Surg. 2008;136:1318-23.

25. Sabashnikov A, Mohite PN, Zych B, et al. Outcomes and predictors of early mortality after continuous-flow left ventricular assist device implantation as a bridge to transplantation. ASAIO J. 2014;60:1629.

26. den Uil CA, Akin S, Jewbali LS, et al. Short-term mechanical circulatory support as a bridge to durable left ventricular assist device implantation in refractory cardiogenic shock: a systematic review and meta-analysis. Eur J Cardiothorac Surg. 2017;52:14 25 .
27. Gustafsson F, Rogers JG. Left ventricular assist device therapy in advanced heart failure: patient selection and outcomes. Eur J Heart Fail. 2017;19:595-602.

28. Hieda M, Sata M, Nakatani T. The importance of the management of infectious complications for patients with left ventricular assist device. Healthcare (Basel). 2015;3:750-6.

Publisher's note Springer Nature remains neutral with regard to jurisdictional claims in published maps and institutional affiliations. 